\title{
Responsabilidad del Estado colombiano en accidentes de tránsito por el mal estado de las vías
}

Responsibility of Colombian state in traffic accidents by the bad state of the tracks

\author{
Responsabilidade de Estado colombiano em acidentes \\ de trânsito por o mau estado das faixas
}

\section{Lizandro Alfonso Cabrera Suarez ${ }^{1}$}

Recibido: 12 de marzo de 2019

Aprobado: 15 de mayo de 2019

Publicado: 30 de junio de 2019

Cómo citar este artículo:

Lizandro Alfonso Cabrera-Suárez. Responsabilidad del Estado colombiano en accidentes de tránsito por el mal estado de las vías. DIXI 29, Enero 2019, 1-20.

DOI: https://doi.org/10.16925/2357-5891.2019.01.02

Artículo de investigación. https://doi.org/10.16925/2357-5891.2019.01.02

1 Magíster en Derecho, Universidad Sergio Arboleda, Bogotá. Abogado, Universidad Santiago de Cali. Investigador júnior, Colciencias. Docente de posgrados, Universidad de la Amazonía y de la Universidad Santo Tomás de Bogotá

ORCID: https://orcid.org/0000-0003-2548-4032

Correo electrónico: Ilzandrocabrera@hotmail.com 


\section{Resumen}

Objetivo: el trabajo realiza un análisis de la responsabilidad del Estado en accidentes de tránsito, generada por el mal estado de las vías, a partir de una caracterización del tema de la responsabilidad.

Metodología: con base en una fundamentación teórica y un estado del arte sobre el tema, realiza un escueto estudio desde el derecho comparativo en materia de investigación.

Resultados: finalmente, defiende una posición contraria, en la cual no siempre existe una responsabilidad objetiva de la administración pública.

Conclusiones. entre otras, la sola comprobación del mal estado de las vías no genera responsabilidad del Estado.

Palabras clave: responsabilidad, responsabilidad civil, responsabilidad jurídica, responsabilidad penal, sanción.

\section{Abstract}

Objective: the work makes an analysis of the responsibility of the State in traffic accidents generated by the poor state of the roads, starting from a characterization of the issue of responsibility.

Methodology: based in a theoretical foundation and a state of the art on the subject. The article presents a brief study from the comparative law in the research subject.

Outcome: finally, it defends a contrary position in which there is not always an objective responsibility of the public administration.

Conclussion: among other, verification of the poor condition of the roads does not generate State responsibility.

Keywords: liability, civil liability, legal liability, criminal liability, sanction.

\section{Resumo}

Objetivo: o trabalho realiza uma análise da responsabilidade do Estado em acidentes de trânsito, gerada por o mau estado das estradas, com base na caracterização da questão da responsabilidade.

Metodologia: com base em uma fundamentação teórica e um estado da arte sobre o assunto, faz uma breve Eu estudo a partir de direito comparado em pesquisa.

Resultados: finalmente, defender uma posição contrária, na qual nem sempre há uma responsabilidade objetiva da administração pública.

Conclusões entre outras, a mera verificação do mau estado das estradas não gera responsabilidade pela Estado.

Palavras-chave: responsabilidade, responsabilidade civil, responsabilidade legal, responsabilidade criminal, sanção 


\section{INTRODUCCIÓN}

La costumbre y la inseguridad jurídica pusieron de moda en Colombia demandar al Estado. Era y resultaba fácil ganar cualquier litigio. Entre otras cosas, porque el ente central poco asistía, y si lo hacía se presentaba sin fuerza al proceso. Hoy el concepto es distinto. Varios son los significados que se le pueden adjudicar a la palabra responsabilidad. Por una parte, proviene del latín responsum, que significa "ser acreedor de una deuda". En el derecho romano su concepción se relaciona con el restablecimiento, la seguridad o la indemnización. En la antigüedad, dicho concepto dependía de juicios tanto naturales como de relaciones humanas, los cuales estribaban, en muchas ocasiones, en las acciones y los efectos que estas traían consigo. De este modo, aquellos actos o ejercicios indebidos significaban las acciones de los hombres, mientras que la responsabilidad se configuraba en una especie de purga que conseguía equilibrar y recomponer las conductas indebidas. Con la desagregación de nociones tales como individuo y vida pública y privada, inmersas en las cuestiones divinas y humanas, afloran conceptos de la responsabilidad dentro de los cuales cabe remarcar la "responsabilidad jurídica", que trae intrínseca en ella la ofensa o la violación a la norma y la sanción. Con dicha definición se hace más visible la causa-efecto de la falta a la norma, la cual supone asumir la responsabilidad de los actos tanto de manera pública como privada en el ámbito religioso, moral, político y jurídico.

Según las normas establecidas por el Estado como mecanismo de control de la sociedad, la responsabilidad jurídica se caracteriza por el uso de la pena como resultado de una violación particular a dicha normativa. Esto se suscita bajo dos premisas: 1) debe haber una comunidad con un comportamiento social en el que la vida y las estructuras económicas primen; y 2) debe existir una autoridad que regule y verifique el cumplimiento de dichas normas preestablecidas.

En la sociedad, al estar esta regulada mediante normas, la responsabilidad jurídica termina por permear en dos ámbitos: la responsabilidad política que se refiere a la presencia de altos mandos y de gobernantes, así como al manejo de lo público como un bien general, un bien del pueblo; asimismo, la responsabilidad jurídica es la que vela por la protección de la vida, la integridad física y los bienes económicos de una comunidad.

Los conceptos de responsabilidad penal y responsabilidad civil, a lo largo de la historia, se han transformado según las necesidades del periodo. Sin embargo, una distinción notoria entre las dos concepciones solo se evidencia frente las dos consecuencias legales que se pueden establecer ante las diferentes acciones indebidas: por una parte, la responsabilidad penal obliga a que se ejecute un castigo, mientras que, por otra, la civil conduce a una reposición o indemnización por la falla o agravio. 
Estás consecuencias se hacen necesarias una vez el Estado asume la regularización de las relaciones sociales y el derecho, reservándose el derecho a participar en las transgresiones que puedan alterar el orden social, de modo que permite la libertad en el aspecto económico en lo que a las relaciones de los particulares se refiere. Es así entonces como el derecho penal y el derecho civil logran diferenciarse, no solo desde la responsabilidad que le atañe a cada uno, sino, además, desde la propia normativa que se aplica según la violación a la norma, la cual conduce y obliga a definir el objetivo, los contenidos y el correctivo a ejercer con la sanción.

El ensayo permitió determinar que no siempre es el Estado responsable por todo accidente sucedido en vía pública. El aporte principal de la investigación fue la demostración en la claridad y en la evolución en el tema de responsabilidad del Estado. Se puede afirmar que hoy, en Colombia, existe un régimen serio y pletórico de seguridad juridica en esta área.

\section{RESPONSABILIDAD JURÍDICA}

La teoría general del derecho se refiere al término de responsabilidad como un concepto en el que las causas y las derivaciones de un acto inapropiado que acarrea consecuencias de tipo jurídicas se manejan dentro de un marco normativo concreto.

En el siglo Xx, el jurista y filoso austriaco Hans Kelsen resalta los conceptos de obligación jurídica y responsabilidad, los cuales se logran identificar dentro de las normas jurídicas. En este aspecto destaca el método y el objetivo que corresponde a la ciencia jurídica, así como la relación de algunas definiciones con las ideas que se tiene respecto a la norma "[...] que una persona sea legalmente responsable de determinada conducta o que sobre ella recaiga la responsabilidad jurídica de la misma, significa que está sujeta a una sanción en el caso contrario"1.

El teórico Kelsen afirma que la responsabilidad está relacionada con la norma y la sanción, es decir, un individuo puede ser castigado por una conducta inapropiada de la cual debe hacerse responsable. Por ende, para este filosofo los términos de responsabilidad, deber y obligación jurídica son los mismos, de modo que obliga con esto a que la responsabilidad solo se tenga en cuenta con miras a acciones que conlleven a una sanción, de forma que no pueden, entonces, ejecutarse en ámbitos jurídicos como, por ejemplo, el de la responsabilidad directa o por resultado en en el que la sanción no entra en vigor.

1 Véase Kelsen, como se cita en Pablo de Larrañaga. EL CONCEPTO DE RESPONSABILIDAD EN LA TEORÍA CONTEMPORÁNEA DEL DERECHO. Doctrina Juridica. (2004). Pág. 4. 
El filósofo de derecho danés Alf Ross menciona que la responsabilidad es un sistema en el que esta exige el pago, es decir, el castigo por una errada conducta, al igual que explicaciones del porqué de la acción de la persona ${ }^{2}$. Esto significa que tanto la responsabilidad como la culpabilidad y el castigo presuponen la violación a una norma, de manera que se considera la culpabilidad tanto un reproche que un individuo lleva consigo por haber violentado una regla en el marco de una sociedad como una noción en la que la amonestación se hace necesaria en conformidad con un sistema legal que asimismo lo requiere ${ }^{3}$. Así, entonces, cuando una persona se comporta de forma errada, o contrariamente a lo que la ley presupone, recibe un especie de castigo en el que debe no solo hacerse responsable de sus actos mediante una sanción, sino que, además, recibe señalamientos y reproches por partes del resto de la comunidad.

Por su parte, Hart cataloga la responsabilidad en relación con la sanción de varias maneras: la define como una capacidad, como una causalidad, como deberes que están intrínsecamente ligados a un comportamiento en la sociedad y, por último, como una sanción misma4.

Este estado de arte evidencia con claridad la necesidad de analizar la institución de la responsabilidad, puesto que las muy diferentes apreciaciones que los distintos autores tienen respecto al concepto de la responsabilidad difieren de manera un tanto abismal. Mientras que el filósofo Kelsen no la diferencia de la obligación jurídica, Ross no deja ver con claridad la responsabilidad objetiva, y Hart se inclina más hacía un campo lingüístico.

\section{RESPONSABILIDAD Y ORDEN JURÍDICO}

La responsabilidad es un término que, en la teoría general de derecho, toma una relevancia inminente en todos los sistemas jurídicos, pues es innegable su presencia en todo lugar que presuponga un grupo de reglas que deben ser llevadas a cabo por una persona. Es así como la causa-efecto aquí toma especial importancia, en la medida en que un individuo debe asumir y responder por toda acción que ejecute y, de un modo u otro, llegue a afectar a otra persona o incluso a un colectivo ${ }^{5}$.

2 Cf. Enrique Gil Botero. TEMA DE RESPonsabiLIDAD EXTRAContractual DEL ESTADO. Tercera Edición. Editorial com Libros y Cía. (2006). Pág. 3.

3 Cf. Larrañaga, supra, nota 1. Pág. 60.

4 Id.

5 Jorge Peirano Facio. Responsabilidad civil extracontractual. Temis. (2004). Pág. 24. 
En el sentido más esencial de la responsabilidad, en el derecho esta se conjuga en la sancionalidad que se le ejecuta a una persona cada que esta lleve a cabo actos $u$ acciones indebidos que requieran de un correctivo.

La obligación y la responsabilidad son inherentes, pues para que una obligación se pueda suscitar es necesario que exista un correctivo que se pueda ejecutar cada que esta se vea infringida. En el derecho civil, la teoría clásica de la responsabilidad establece una clara distinción de la articulación que existe entre el derecho y la obligación, es decir, no se puede dejar entrever la relación presente entre aquel individuo que desconoce su obligación jurídica y aquel que se ve afectado por el acto con que el otro le está afectando.

La obligación, desde el ámbito legal, se refiere a aquella relación que se suscita entre dos individuos y por la que uno se convierte en un deudor -el cual debe cumplir una prestación objeto o una reparación por daños y perjuicios que haya podido ocasionar con alguna acción-, mientras la otra se configura como beneficiaria o acreedora de dicha acción. Es importante resaltar que la principal característica en una obligación legal es el objeto, pues este puede ser simplemente una prestación de un servicio, al igual que puede convertirse en una retribución por una acción por parte de un deudor a un acreedor.

Las obligaciones presentan dos orígenes: los actos jurídicos y los hechos jurídicos. Los hechos jurídicos son imputables al hombre y estos, a su vez, pueden ser tanto lícitos como ilícitos. Los hechos jurídicos lícitos son aquellos que se suscitan sin que se presente una violación a la normativa impuesta por ley, mientras que los hechos jurídicos ilícitos se diferencian por el incumplimiento a las obligaciones o normas, lo cual requiere entonces de una reparación por los daños y perjuicios que dicha violación puede ocasionar. Esto en razón a que el individuo es una persona civil responsable y, desde su responsabilidad legal, debe hacerse cargo de los detrimentos o menoscabos a terceros.

El jurista colombiano Javier Tamayo Jaramillo señala: "la responsabilidad civil engloba todos los comportamientos ilícitos que por generar daño hacen recaer en cabeza de quien los causó, la obligación de indemnizar"6. Es así, entonces, como la responsabilidad civil se considera una acción reparadora que permite de un modo $u$ otro recuperar aquella armonía que se ha visto alterada debido al autor de la violación o el perjuicio. Existen unos elementos comunes y esenciales de toda forma de

6 Véase Javier Tamayo Jaramillo. LA RESPonSABILIDAD DEL ESTADO: EL RIESGo EXCEPCIONAL Y LAS ACTIVIDADES PELIGROSAS. EL DAÑO ANTIJURÍDICO (CONST. POL., ART.90). Editorial Temis S. A. (2000). Pág. 9. 
responsabilidad: la conducta realizada por el acto del daño, el daño cierto, personal y antijurídico, y el nexo causal entre la conducta y el daño.

En el derecho civil la responsabilidad presenta dos expresiones claras en las que los daños o menoscabos no necesariamente se suscitan de una relación entre las dos partes (acreedor o deudor o del incumplimiento de un contrato). Dichas manifestaciones se pueden catalogar como "responsabilidad contractual" y "responsabilidad extracontractual".

Referente a lo anterior, cuando un derecho se viola es posible evidenciarlo desde dos tipos de lesiones: 1) una lesión sobre un derecho de crédito que se suscita por contratos (es aquí cuando se presenta responsabilidad extracontractual); y 2) una lesión al derecho subjetivo en la que existe una relación contractual. Esta última surge como un sustituto de la venganza privada, en la que esta se ejerce sobre el patrimonio y no la persona. Esta clasificación del derecho tuvo su origen en el derecho romano.

Así, no son dos responsabilidades civiles diferentes, es una sola. Estas se regulan bajo los mismos elementos o principios. En la responsabilidad contractual el daño recae sobre un derecho absoluto, de modo que se distingue siempre y desde un inicio quién es el deudor y quién el acreedor, mientras en el extracontractual no se puede evidenciar desde el inicio quién es el responsable, lo que hace necesaria su distinción, ya que dicho individuo no suele ser consciente del derecho correlativo que existe.

\section{LA RESPONSABILIDAD CIVIL EN EL ORDENAMIENTO JURÍDICO COLOMBIANO}

Los artículos 2341 al 2360 del Código Civil regulan la obligación a reparar con respecto a la responsabilidad física, mas no la responsabilidad del sujeto jurídico. Esto hace necesario la regulación de las relaciones entre personas naturales y, por tanto, se aplican los artículos 2357 y 2349 del Código Civil.

La Corte Suprema de Justicia, mediante las sentencias de octubre 26 de 1896 y octubre 20 de 1998 adopta los artículos 2347 y 2349 del Código Civil, con los cuales busca adoptar la responsabilidad indirecta en el ámbito del derecho privado y público?. Las normas del Código Civil sobre la responsabilidad extracontractual en personas jurídicas y privadas asumen una responsabilidad directa según su artículo 2841, y asumen también una responsabilidad por la falla del servicio de las personas de derecho público con el Estado que, como organismo, se emancipa sobre los individuos en

7 Cf. López. (1977), citado por Corte Suprema de Justicia. SENTENCIA 11150. (M.P.: José Roberto Herrera; octubre 20 de 1998). Pág. 35. 
la medida en que cado uno de estos tiene una función en relación con la de personas morales, privadas y públicas.

La responsabilidad indirecta es la que afecta a terceros debido a las violaciones o trasgresiones efectuadas por individuos en ejercicio de sus funciones públicas. Según los artículos 2341 y 2349 del Código Civil, cuando se ejecutan infracciones por parte de dichos funcionarios la responsabilidad recae sobre el ente público, ya que la persona jurídica debe ser un garante y vigilante de la calidad del personal que está bajo su mando. La jurisprudencia civil aplica los mismos artículos para conjugar lo que le corresponde a las entidades públicas, por supuesto, en relación con el agravio o la falla cometida.

La responsabilidad civil busca indemnizar por los agravios que conllevan una acción que termina por afectar el patrimonio de un individuo. El Código Civil colombiano establece, en su artículo 2343: "Es obligado a la indemnización el que hizo el daño y sus herederos".

En la actualidad civil, está en miras de la protección de los agraviados, lo que ha incidido en la búsqueda y la creación de mecanismos de protección constitucional, legal y jurisprudencial que le den pie a las víctimas para que puedan hacer valer los respectivos derechos que han sido violados y recibir así, a su vez, una compensación por el agravio.

\section{LA RESPONSABILIDAD DE LA ADMINISTRACIÓN PÚBLICA}

\section{A. Etapa I}

La noción de responsabilidad extracontractual del Estado, que se deriva de la clásica responsabilidad civil, a lo largo del tiempo ha presentado un desarrollo teórico interesante por el cual ha llegado a un punto en el que ha logrado un fundamento legal dentro de la Constitución Política colombiana. La responsabilidad del Estado en un principio no era garante o responsable por las acciones que conllevaran a daños causados debido a la aplicación de su poder imperioso y perene, lo que evidenciaba la incapacidad del Estado. De esta manera, el primero al mando solo respondía ante su divinidad o ante aquel que le brindase su poder. Los pueblos no tenían el poder que les permitiera lograr que se les indemnizara por los daños y perjuicios que cualquier soberano pudiese ejecutar. 
En este periodo, los conceptos de responsabilidad y soberanía se excluían. Anota el profesor Duguit (como se cita en Urueta):

Es evidente que tomadas en si las dos nociones de responsabilidad y de soberanía son antinómicas, porque si el Estado se considera soberano no puede admitirse que sea responsable y si se afirma que es responsable, no puede admitirse que sea soberano. O la soberanía es nada, o ella es, como se ha dicho, ese rasgo de voluntad que no se determina sino por sí misma, es decir, que no puede limitarse por un elemento extraño, ni sometido a obligaciones sino en la medida en que es consentida. De ahí resulta que una persona soberana no puede ser responsable de sus actos, esto es, sometida a una obligación que se imponga a ella desde el exterior, o por lo menos no puede serlo en la medida en que lo quiera ${ }^{8}$.

Según el profesor Irisarri甲 ${ }^{9}$ el soberano no estaba sujeto a cometer errores, de modo que tenía la total confianza puesto que se identificaba con el Estado. Es por esto que no era posible concebir al monarca como responsable de los daños y los perjuicios que sus acciones pudiesen acarrear.

El término soberanía, a lo largo de la historia, ha evolucionado debido a los pensamientos dominantes del momento. El primer concepto que se manejó fue el de concepción teocrática, el cual asumía al soberano como el heredero de un poder divino. Esto se basaba en una tradición con muchos siglos de existencia en la que se asumía que el poder de un monarca no conllevaba al ejercicio ilícito, es decir, que sus acciones nunca dañaban a la sociedad en la que este estuviese inmerso ${ }^{10}$.

La irresponsabilidad del Estado que se suscitaba debido a las concepciones teocráticas y democráticas, según la cual el soberano era el poseedor del poder absoluto, se comenzó a difuminar en el siglo XVIII cuando empezaron a nacer diferentes teorías democráticas en las que la voluntad general se exponía como la máxima expresión de poder en la sociedad política, con lo que se generó el inicio de una ruptura con el principio de irresponsabilidad del poder público.

8 Véase Manuel Urueta. La responsabilidad extracontractual del Estado. En RECOPILACIÓN UNIVERSIDAd SANTO TOMAS DE BUCARAMANGA. Universidad Santo Tomas. (2005). Pág. 3.

9 Cf. Antonio José de Irisarri. LA RESPONSABILIDAD DE LA ADMINISTRACIÓN PÚBLICA POR FALLA O CULPA DEL SERVICIO EN COLOMBIA. LA RESPONSABILIDAD DE LA ADMINISTRACIÓN PÚBLICA. Universidad Externado de Colombia. (1986). Pág. 143.

10 Cf. Eduardo García de Enterría y Tomás Ramón Fernández. CuRSo DE DERECHO administrativo. Tomo II. Civitas. (1993). Pág. 361. 


\section{B. Etapa ॥}

La irresponsabilidad del Estado exhibió varias restricciones, ya que se presentaron casos en los que el Estado debería haberse hecho responsable de agravios o violaciones que se ejecutaron por acciones en alguna de sus muchas gestiones, pero no lo hizo.

El docente argentino Julio Altamira argumentó en su investigación varias teorías sobre la responsabilidad del Estado por daño ${ }^{11}$. Hace mención a la teoría de la ficción de Savigny en la que el Estado se hace responsable de ciertas acciones que están en el marco de unos límites estatutarios, lo cual no deja cabida a actos de responsabilidad ilícita, pues estos los ejecuta un representante que se encuentra fuera del mandato y no puede entrar a sancionarse a una persona jurídica por las acciones que ha llevado a cabo su representante.

La teoría organicista que surge después habla de funcionarios públicos, los cuales hacen parte de un gran estamento. Dicha organización recibe el nombre de "administración pública", y cuando uno de sus funcionarios comete una falta es a la administración como tal a quien se le imputan los diferentes cargos.

Teissier se refiere a una teoría de la proporcionalidad de cargas ${ }^{12}$, en las que el equilibrio determina la responsabilidad de la administración pública por sus actos. Cuando la administración lesiona o damnifica a un habitante, esta repara el daño sin romper el principio de igualdad que debe funcionar para todos y cada uno de los ciudadanos de una sociedad. Según el docente Álvaro Castro, este derecho se ejecutó en el derecho alemán bajo el nombre de "criterio de la carga desigual o especial del particular sacrificio". Esta se encuentra fundamentada en los derechos del hombre y del ciudadano, que sostienen, en su artículo 78, que "[...] unos ciudadanos no deben sufrir más que otros las cargas impuestas en interés de todos"13.

El docente Alatamira incluso propuso su propia teoría del bien común, según la cual el bien común es el que prima, por tanto, la responsabilidad del Estado no resulta ser efectiva si uno de los miembros de su sociedad ha sido vulnerado por acciones que la administración ha ejercido sobre ella. Esto hace necesario que surja una indemnización que, de igual forma, regrese el equilibrio correspondiente a la comunidad ${ }^{14}$.

11 Cf. Julio Altamira. La ReSPonsabilidad estatal POR daño. (2011). Pág. 5. Disponible en http://www.acaderc.org.ar/doctrina/articulos/artdanoaltamira/at_download/file

12 Id.

13 Véase Álvaro Castro. LA RESPONSABILIDAd PATRIMONIAL DEL ESTADo EN MÉXICO. FUNDAMENTO CONSTITUCIONAL Y LEGISLATIVO. Biblioteca jurídica virtual del Instituto de Investigaciones jurídicas de la UNAM. (2007). Pág. 536. Disponible en www.juridicas. unam.mx.

14 Cf. Julio Altamira, supra, nota 11. Pág. 537. 


\section{B. Etapa III}

La evolución del Estado como una organización administrativa pública conllevó al surgimiento de los conceptos de actos de servicio público y actos ajenos al servicio público. Aquí el Estado participa al buscar el desarrollo o el logro de sus fines, y pasa así al mismo tiempo a ocasionar menoscabos en la propiedad de los administradores.

Es de este modo que se origina la tesis de la falla, según la cual el Estado, al ser garante de la prestación a los ciudadanos de unos servicios públicos, termina por convirtirse en el responsable a la hora de responder por los daños que pueda causar una mala ejecución o un mal funcionamiento de dichos servicios. De este manera, el intervencionismo del Estado termina por originar la conversión del Estado como responsable contractual.

Se hacen entonces dos diferenciaciones de responsabilidad que son importantes: 1) el Estado se asume responsable cuando se presenta una falla por la prestación del servicio; y 2) el agente asume el error, solo en el caso en que este se excede con sus funciones al punto de incurrir en una falla.

La teoría de la responsabilidad por riesgo de Duguit ${ }^{15}$, en cambio, afirma que la responsabilidad de la administración se da una vez se brinda un mal servicio o se presenta un daño con los servicios públicos que termina por afectar a un individuo cualquiera.

Mayer ${ }^{16}$ propuso una teoría de la equidad en la que el Estado solo indemniza en el caso en el que el individuo afectado cumpla las siguientes exigencias: 1) que el perjuicio sea ocasionado por la administración; 2) el individuo se viese afectado al punto de recibir una sanción que lo ponga en desventaja con el resto de los pares de su sociedad; y 3) exista un daño material.

Por otra parte, la teoría de la estricta justicia de Sarria argumenta que la responsabilidad del Estado se hace efectiva una vez este tiene tanto servicios como personas a su cargo, independientemente de carencia o falla de los primeros ${ }^{17}$.

Altamira también propuso su propia teoría18: la tesis de la solidaridad humana, la cual argumenta que la responsabilidad del Estado está inmersa en la solidaridad del hombre, en una acción cadena en la que todos los individuos de una sociedad se dan la mano de manera recíproca. Sus fuentes se basan en la justicia distribuida que una sociedad debe llevar a cabo con aquellas personas que se encuentran en difíciles o desmejoradas condiciones con respecto al resto de su comunidad.

\footnotetext{
15 Id. Pág. 12.

16 Id. Pág. 13.

17 Id.

18 Id. Pág. 14.
} 
Según Castro ${ }^{19}$, las teorías del enriquecimiento ilegítimo de Haurióu en Francia y la del particular sacrificio defendida en Alemania por Forsthoff, también abordan el tema.

En suma, la teoría de la responsabilidad del Estado funcionaba dependiendo de la mirada que se le daba al Estado. Por una parte, el Estado en cuanto ente responsable de las falencias o agravios que tanto sus entes como sus agentes pudieran ejecutar, o como un organismo que, de manera indirecta, termina por asumir la responsabilidad por todas esas personas que se encuentran bajo su mando. La teoría también siguió su desarrollo con respecto a las normas que regían las acciones del Estado, es decir, si la responsabilidad de sus acciones estaba sujeta a la responsabilidad de los particulares o la regulaba una normativa exclusiva y especial.

\section{FUNDAMENTOS DE LA RESPONSABILIDAD DEL ESTADO DESDE EL DERECHO COMPARADO}

En principio, la responsabilidad de la administración en Francia excluía al Estado de indemnizar y solo daba garantía al individuo agraviado cuando había responsabilidad directa del funcionario, según lo dictaban las normas de derecho civil. Para que un individuo pudiese demandar al funcionario por la vía civil era necesario tener una autorización administrativa previa, pues solo así era exigible la responsabilidad directa de este. Es aquí entonces en este punto en el que nace la responsabilidad patrimonial de la administración, y el Estado francés solo reconocía dicha responsabilidad siempre y cuando se logrará comprobar el agravio, de modo que se permitía dirigir una acción en contra de la administración.

La responsabilidad patrimonial de la administración evoluciona al limitar la responsabilidad personal del funcionario a cuando este comete agravios con intención alguna de causar daño, y cuando está alejado de la prestación de todo servicio público. La administración solo acepta agravios cuando se evidencia que la falta o falla cometida no es personal por parte de algún funcionario. Solo los errores o la negligencia en la prestación del servicio público debe asumirlos la administración, la cual debe entrar a reparar los daños o perjuicios cometidos.

El Fallo Blanco de 1873 estableció el principio general de la responsabilidad de la administración de manera autónoma e independiente de lo contemplado en el Código Civil que reglamenta las relaciones entre particulares, de manera que amplía la responsabilidad de la administración a cualquier clase de servicio o daño que sea

19 Cf. Álvaro Castro, supra, nota 13. Pág. 538. 
atribuible a acciones de personas bajo su cobijo o por cosas que se encuentran bajo su resguardo, siempre y cuando no exista una relación directa entre la actividad del organismo público y el daño causado ${ }^{20}$.

En España, cuando el daño provenía de sus funcionarios pasa de la irresponsabilidad absoluta a la responsabilidad de la administración, con lo que le da un rango constitucional a la responsabilidad subsidiaria de la administración y pasa así a pagar, incluso si el agravio proviene de uno de sus agentes que faltan a la norma desde su cargo.

La Ley de Expropiación Forzosa de 1954 estipuló la responsabilidad patrimonial de la administración al extender su alcance a todas los órganos administrativos. La indemnización por faltas o agravios en la prestación normal o anormal de servicios públicos a particulares tanto en bienes como en los derechos que les corresponden se definió en el artículo 121 de la LEF.

A continuación, por medio de algunas leyes generales, en España se instituyó una clausula general de cobertura patrimonial de los administradores (Ley 27 de diciembre de 1956), sobre la cual se construyó todo el sistema de responsabilidad civil de la administración, lo cual produjo múltiples levantamientos del Consejo de Estado.

Con el anterior planteamiento que se obtuvo de la Constitución de 1978, se establece la responsabilidad directa de la administración frente a daños o perjuicios producidos tanto por la administración como por los funcionarios públicos, debido a malos funcionamientos de los servicios públicos, al igual que perjuicios suscitados por acciones lícitas de la administración o el funcionamiento corriente del servicio público que genere menoscabo. Se establece entonces una responsabilidad de la administración, la cual debe indemnizar a todo individuo que sufra agravios en sus bienes y derechos como consecuencia del funcionamiento de los servicios públicos.

El Tribunal de Francia legitima por vez primera la autonomía de la responsabilidad del Estado, no contemplando entonces en las normas contenidas en el código civil sino en unas reglas especiales, las cuales fueron elaboradas por un juez administrativo mediante el Fallo Blanco, el cual se considera el cimiento del derecho administrativo.

En el Fallo Blanco se declaró que "[...] la responsabilidad que puede incumbirle al Estado por los daños causados a los particulares como consecuencia de los hechos de las personas que emplea para el servicio público no puede estar regida por los principios establecidos en el Código Civil para las relaciones entre particulares"21.

Del contenido del Fallo Blanco se destacan dos elementos. De acuerdo con los tratadistas Long, Weil y Braibant:

20 Cf. Esguerra. (2008). Pág. 259.

21 Id. 
La razón básica para sustraer la responsabilidad del Estado de la esfera propia del Código Civil, fue la necesidad de conciliar intereses de la colectividad en la correcta prestación de los servicios públicos, con los de los particulares que pudieran verse afectados por una falla en la correcta prestación; y de otra parte, el carácter excepcional que el fallo quiso darle a la responsabilidad del Estado por fallas en la prestación de los servicios públicos, en la que la responsabilidad no es general ni absoluta, con los cual quiso expresar que la autonomía de la responsabilidad del derecho administrativo implicaba, menor favorabilidad para los particulares frente a las soluciones que daba el Código Civil22.

La autonomía de la responsabilidad del Estado se configuró sobre la "culpa", al igual que en la responsabilidad civil de los particulares. Solo cuando se podía demostrar el menoscabo a un individuo generado por culpa del Estado era que se le podían adjudicar la responsabilidad en los hechos. Después del Fallo Blanco, la responsabilidad del Estado es atribuida a este, independientemente de que el acto de agravio estuviese dentro del marco de su poder o gestión o en la falla de un servicio público.

El Estado se hace responsable cuando en la ejecución o en la gestión de sus poderes legales se ha sobrepasado, o cuando se presenta un mal funcionamiento de un servicio, o bien porque este no se presta o, en su defecto, cuando se evidencian averías o retrasos en su funcionamiento. Para la aplicación de esto se tuvieron en cuenta los artículos 2347 y 2349, los cuales reglamentaban la responsabilidad indirecta de un individuo a causa de aquellas acciones ejecutadas por aquellos quienes estuvieran bajo su cargo, extendiéndose luego a la responsabilidad del Estado por culpa de sus funcionarios. La responsabilidad del Estado fue por muchos años una responsabilidad civil contractual, la cual se regía por el artículo 2341 del Código Civil. Si se tiene en cuenta que la culpa de los funcionarios era asumida por el Estado, se empezó a hablar de una responsabilidad directa de la administración.

Cuando deja de tenerse en cuenta la culpa como un fundamento elemental dentro de la responsabilidad, el Estado pasó a reconocerse como responsable patrimonial. Fue en este momento que se comenzó a hablar de la responsabilidad por falta o falla en el servicio público, con lo cual se diferenciaba de lo contemplado en el Código Civil. Es importante recalcar que el Fallo Blanco no otorgó una autonomía total de normas a la responsabilidad de la administración, caso contrario al que estableció con el derecho administrativo, en el cual no necesariamente todo agravio o falla termina por ser responsabilidad total de la administración, puesto que hay un

22 Cf. Antonio José de Irisarri, supra, nota 9. Pág. 145. 
equilibrio en las cargas públicas. Esta teoría no se aplica en el derecho civil, en el que un funcionario por la no prestación adecuada del servicio pasa a ser directamente responsable, mientras que si se considera como empleado sujeto a las norma de derecho privado sí lo sería.

Respecto a otros temas, en el acercamiento que se da entre las teorías civiles y administrativas de responsabilidad, como, por ejemplo, el reconocimiento de la responsabilidad del Estado en acciones ejecutadas por sus funcionarios que desobedecen las órdenes recibidas en ambos regímenes, se aplica la teoría del "aviso de funciones".

Sobre la originalidad de la responsabilidad del Estado manifiesta el profesor Vedel:

[...] la responsabilidad pública no presenta, a pesar de las diferencias, ninguna originalidad del fondo en relación con la responsabilidad privada. Es exacto que la autonomía del derecho administrativo es mucho más perceptible si se examina la teoría de los contratos administrativos que si se examina a la de la responsabilidad ${ }^{23}$.

Así logra consolidarse una diferencia cuando los perjuicios eran propiciados por actos de carácter personal de un funcionario público en los que la culpa se articulaba con el desarrollo de una función que estuviese relacionada con el Estado. El régimen jurídico de responsabilidad patrimonial asumió de igual forma la responsabilidad por faltas o fallas en el servicio público, de lo cual se resalta que es necesario en este punto demostrar que la falla como tal no concierne a una falta personal de un funcionario, sino a un acto irregular propio de la administración.

Aunque la teoría de la falla del servició consiguió un avance significativo con relación a la adjudicación de la responsabilidad del Estado, se empiezan a reflejar fallas que, si bien no correspondían de manera directa a la administración, sí era hacía necesario que este respondiera por los perjuicios que pudiese estar generando, puesto que se presentaban casos en que no era posible demostrar la falla del servicio o de su integración impensada con los daños. A partir de aquí se empieza entonces a aceptar la presunción de la falla del servicio, así como se tiene en cuenta en algunos casos la responsabilidad del Estado, aun cuando este no hubiese accionado de manera ilícita, mas si se causa un daño que el individuo no es capaz de soportar.

23 Véase Georges Vedel. DERECHO ADMINISTRATIVo. Biblioteca Jurídica Aguilar. (1980). Pág. 279. 
Por cerca de 20 años, el Consejo de Estado se refirió a la falla del servicio como un fundamento de la responsabilidad patrimonial del Estado, e incluyó en esta noción todo aquel evento en el que la administración accionara una falla, un retraso, una falta o una omisión en el ejercicio de sus obligaciones. Dado que no en todas las situaciones resultaba posible la compensación por acciones que cometiesen daños y perjuicios, dicho estamento inició la formulación de diferentes medidas especiales, como, por ejemplo, la responsabilidad que tienden hacía la responsabilidad objetiva, sin que estuviese presente en esta la culpa. Ejemplos claros de estos eventos son la responsabilidad por daño especial, el riesgo excepcional y algunas excepciones en las que no resultaba fácil la comprobación de la falla del servicio o esos hechos en los que sin actos ilícitos existía un perjuicio que no resultaba fácil de soportar.

\section{RESPONSABILIDAD EN LA CONSTITUCIÓN POLÍTICA}

Mientras estuvo en vigor la Constitución de 1886, el Estado administrador resultaba ser el total responsable del no cumplimiento de contratos y de aquellas acciones que generaran daños y perjuicios a terceros, aun cuando no estaban contemplado en los contratos. No existía una norma que le impusiera a un agente público resarcir los daños que este pudiese ocasionar a un individuo.

Una vez el Consejo de Estado se apersonó del conocimiento de las demandas de responsabilidad de la administración, en virtud de la Ley 167 de 1941, se empezó a generar una división que reglamentaba la responsabilidad contemplada en el derecho privado y refuerza su jurisprudencia con base en los artículos $2^{\circ}, 16$ y 30 de la Constitución Política de 1886, tal como lo hizo La Corte Suprema de Justicia al consagrar el principio de legalidad, el deber del Estado de proteger la vida, la honra y los bienes de los ciudadanos, así como la garantía de la propiedad privada y de los demás derechos adquiridos con justo título.

Establecía el artículo 16 de la Constitución Política, reformado por el Acto Legislativo N.․ 1 de 1936, lo siguiente: "Las autoridades de la República están instituidas para proteger a todas las personas residentes en Colombia, en su vida, honra y bienes, y para asegurar el cumplimiento de los deberes sociales del Estado y de los particulares" 24 .

24 Véase Carlos Restrepo. CONSTITUCIONES POLítICAS NACIONALES DE COLOMBIA. Universidad Externado de Colombia. (1995). Pág. 439. 


\section{ANTECEDENTE JURISPRUDENCIAL}

El Consejo de Estado, por medio de la teoría de la imputación de la responsabilidad y a través del término de la falla del servicio, adopta un papel determinante para demarcar y evidenciar la responsabilidad del Estado. Consideró el alto tribunal, en sentencia de abril 18 de 1997:

Es primer deber del Estado, procurar la realización del bien común, propósito consagrado en el artículo 16 de la Constitución; para ello dispone y organiza los Ilamados servicios públicos. Si como consecuencia de un mal funcionamiento del servicio, o de su no funcionamiento o del tardío funcionamiento del mismo se causa lesión o daño, el Estado es responsable, y por consiguiente está en la obligación de indemnizar los perjuicios ocasionados. La responsabilidad se origina en último término en el deber primario del Estado de suministrar a los asociados los medios conducentes a la efectividad de sus servicios, a la consecución de sus fines, en otras palabras, a la realización del bien común.

Colombia, en la Constitución Política de 1991, expresa la responsabilidad patrimonial del Estado como noma constitucional.

En la Sentencia c-333 de 199625, con respecto a la consagración de una norma expresa de responsabilidad del Estado en el ordenamiento constitucional, la Corte Constitucional sostuvo: "Antes de la carta del 1991 no había norma expresa sobre la responsabilidad patrimonial, pero ahora y especialmente el articulo 90 superior lo define con claridad".

El artículo 90 de la Constitución Política de 1991 estableció la Cláusula General de Responsabilidad, la cual expresa: "El Estado responderá patrimonialmente por los daños antijurídicos que le sean imputables causados por la acción u omisión de las autoridades públicas"26. Así, la responsabilidad del Estado se transforma en uno de los cimientos del Estado de derecho, de modo que se convierte en una garantía ciudadana fundamental, según lo manifestó en su momento el constituyente y ponente de la iniciativa, el doctor Esguerra Portocarrero.

Dentro la norma constitucional existe una regla general de responsabilidad patrimonial del Estado bajo la premisa de lo nocivo que resulta la indemnización

25 Véase Corte Constitucional de Colombia. SENTENCIA C-333/96. (M.P.: Alejandro Martínez Caballero; agosto 1 de 1996).

26 Cf. Juan Carlos Esguerra Portocarrero. LA PROTECCIÓN CONSTITUCIONAL DEL CIUDADANO (2008). Legis. Pág. 300. 
de cualquier acción ilícita, para lo cual se basa en la protección y la garantía de los derechos de los dirigidos y no pierde de vista la responsabilidad o el sistema de responsabilidad precontractual y la responsabilidad patrimonial del Estado de carácter contractual.

Según la Sección Tercera del Consejo de Estado, en caso de daño la sola comprobación del mal estado de la vía no es suficiente para expresar la responsabilidad patrimonial del Estado. Dicha comprobación debe sustentarse con la refrendación del motivo que causó la falla y la acción u omisión que pudo haber presentado la administración en caso de requerirse un respectivo mantenimiento a la malla vial. La Sección Tercera hizo salvedad de que en caso de haberse requerido mantenimiento, el no cumplimiento de la labor lo hace responsable de aquello que pueda ocurrir:

- Cuando el Estado sea conocedor de los altos riesgos de desprendimiento de materiales de las montañas aledañas a las carreteras, y aun así no tome las respectivas medidas para evitar que la acción natural suceda.

- Cuando el Estado no realice el respectivo mantenimiento y conservación rutinaria y periódica de la malla vial, responsabilidad que será más severa en caso de comprobarse que enterada la entidad, dichos daños u obstáculos estuvieron en la carretera por un tiempo considerado razonable para actuar.

En este caso, debe entrarse a analizar el caso de manera particular, así como tener en cuenta las condiciones y las circunstancias bajo las que se desarrolló. En caso de que la valoración arrojada demuestre que los daños que la malla vial presentaba ya habían sido puestos en conocimiento de la accionada, y que está omitió el cumplimiento de sus deberes, las medidas a tomar deben ser aún más estrictas. De igual forma, se aclara que la falta de aviso a la entidad no la exonera de su responsabilidad.

\section{CONCLUSIONES}

El Estado colombiano aprendió a defenderse. Hoy se cuidan los recursos del erario y se propende a mostrar diligencia y cumplimiento de los fines y obligaciones constitucionales.

La jurisprudencia acepta la obligación del Estado de mantener el buen estado de las vías públicas por ser parte del servicio que debe ofrecer, sin embargo, se analizan y estudian las actividades y acciones de las víctimas. Es imposible controlar a 
cada uno de los usuarios de las vías e impedir, por ejemplo, el exceso de velocidad o el uso de bebidas alcohólicas, como tampoco el perfecto estado de los vehículos.

En fin, la sola comprobación del mal estado de las vías no genera responsabilidad, debe demostrarse la acción, la omisión o la falla en el servicio que produjo el accidente.

\section{REFERENCIAS}

Álvaro Castro. LA RESPONSABILIDAD PATRIMONIAL DEL ESTADO en MÉXICO. FUndAMENTO CONSTITUCIONAL Y LEGISLATIVO. Biblioteca jurídica virtual del Instituto de Investigaciones jurídicas de la UNAM. (2007). Disponible en www.juridicas.unam.mx.

Antonio José de Irisarri. LA RESPONSABILIDAD DE LA ADMINISTRACIÓN PÚBLICA POR FALLA O CULPA DEL SERVICIO EN COLOMBIA. LA RESPONSABILIDAD DE LA ADMINISTRACIÓN PÚBLICA. Universidad Externado de Colombia. (1986).

Carlos Restrepo. Constituciones Políticas Nacionales de Colombia. Universidad Externado de Colombia. (1995).

Corte Constitucional de Colombia. SentenciA C-333/96. (M.P.:Alejandro Martínez Caballero; agosto 1 de 1996).

Corte Suprema de Justicia. SENTENCIA 11150. (M.P.: José Roberto Herrera; octubre 20 de 1998).

Eduardo García de Enterría y Tomás Ramón Fernández. CURSO DE DERECHO AdminISTRATIVo. Tomo II. Civitas. (1993).

Enrique Gil Botero. Tema de RESPonSABILIDAD EXTRACOntRACtUAL DEL ESTADO. Tercera Edición. Editorial com libros y Cía. (2006).

Georges Vedel. Derecho Administrativo. Biblioteca Jurídica Aguilar. (1980).

Javier Tamayo Jaramillo. LA RESPONSABILIDAD DEL ESTADO: EL RIESGO EXCEPCIONAL Y LAS ACTIVIdAdES PEligrosas. El dAÑo ANTIJURídico (CONST. Pol., ART.90). Editorial Temis S. A. (2000).

Jorge Peirano Facio. ResponsabiLIDAD CIVIL EXTRACONTRACtUAL. Temis. (2004).

Juan Carlos Esguerra Portocarrero. LA PROTECCIÓN CONSTITUCIONAL DEL CIUDADANO. (2008). Legis. 
20 Responsabilidad del Estado colombiano en accidentes de tránsito por el mal estado de las vías

Julio Altamira. LA RESPONSABILIDAD ESTATAL POR DAÑO. (2011). Disponible en http://www.acaderc. org.ar/doctrina/articulos/artdanoaltamira/at_download/file

Manuel Urueta. La responsabilidad extracontractual del Estado. En RECOPILACIÓN UNIVERSIDAD Santo Tomas de Bucaramanga. Universidad Santo Tomas. (2005). Pág. 3.

Pablo de Larrañaga. EL CONCEPTO DE RESPONSABILIDAD EN LA TEORÍA CONTEMPORÁNEA DEL DERECHO. Doctrina Jurídica. (2004). 